\title{
Reclaiming the Practical: Formal and Substantive Rationality in Social Work Practice
}

\author{
Mary Ellen Kondrat \\ Michigan State University
}

\begin{abstract}
In this article, $\mathrm{I}$ argue that the starting point for inquiry about practice knowledge should be the empirical question, How does the competent practitioner go about knowing "in" practice? Using the work of Jürgen Habermas, Michael Polyani, Donald Schon, and others, I advance a claim for the nonderivative status of substantive rationality alongside the technical in the construction of professional knowledge. I maintain that the researcher and practitioner have functionally different relationships to the practice arena and, therefore, differing cognitive interests for their involvement in that arena. These interests are assumed decisive for (1) categories in which knowledge is structured, (2) methods by which truth claims are authenticated, (3) the type of discourse in which knowledge is communicated, and (4) the mode in which knowledge is available to the knower.
\end{abstract}

The professional school of social work builds its raison d'être on the notion that theoretical knowledge can be translated into skills and know-how for practice. In the prevailing view, knowledge generated and disseminated in the academy is applied to problems faced in the practice arena. ${ }^{1}$ The language of technology (applied research) is the metaphor of choice for the relationship assumed to exist between the achievements of the academic, on the one hand, and the work of the practitioner, on the other. From the perspective of this metaphor, the role of the researcher-theoretician is to produce and authenticate knowledge, whereas the role of the practitioner is to apply

Social Service Review (June 1992).

(C) 1992 by The University of Chicago. All rights reserved.

0037-7961/92/6602-0002\$01.00 


\section{Social Service Review}

knowledge. Thus, practical knowledge becomes derivative. It is the technical or scientific application of formal knowledge. By and large, this construction of the theory-practice relationship is endorsed as normative, although it is usually conceded that the formulation is an ideal toward which the profession aspires, rather than an empirical accomplishment.

The existence of a certain amount of discontinuity between theory and research, on the one hand, and practice, on the other, has long been a preoccupation in the literature. ${ }^{2}$ Historically, efforts to deal with the theory-to-practice tension have taken a number of directions. The several debates may be grouped roughly but, for our purposes, conveniently into three categories. (1) Initially, the literature identified and debated a need for more accountable, hence, more "scientific," approaches to practice. This literature included exhortations for the social work professional to become more diligent in making connections between theory and practice and to become increasingly systematic in evaluating practice outcomes. ${ }^{3}$ (2) Following the initial calls for more scientific-based practice, commentators began proposing concrete suggestions for generating research and building theory within practice settings. Among other topics, this group of articles advanced a case for the single-subject design as the research model most suitable for use by the practitioner. ${ }^{4}$ (3) More recently, the debate was enjoined over dominant philosophical paradigms in social work knowledge and research. This literature deliberated the merits of positivism as the paradigmatic ideal for the conduct of social science. ${ }^{5}$

Despite their differences, partisans to each side of the various debates regarding professional knowledge share a common ground. They are concerned about the task of establishing knowledge that is valid and reliable with reference to the practice world and "user friendly" for the practitioner. Although on the surface this formulation of the task appears to be an unexceptionable one, it is, in fact, partial and onesided in the assumptions made about practice knowledge. In the effort to more successfully wed research and theory to practice, authors in social work and social work education have discussed knowledge and inquiry "for" and "about" and even "in" practice. What has been missing from our collective conversation concerning practice knowledge is an empirical study of practice knowledge itself. ${ }^{6}$ What does the competent practitioner know, and how does he or she know it? What does the practitioner think, and how does he or she go about constructing thought? What are the processes by which practice decisions are made? These and similar questions have received limited attention in the literature, but they are crucial to furthering our dialogue on the relationship between theory and action. ${ }^{7}$

Instead of beginning this inquiry about practice knowledge with definitions of knowledge "for" practice, I argue that the starting point 
should be the empirical question, How does the competent practitioner go about knowing "in" practice? ${ }^{8}$ Such a perspective would reverse the usual order of business, which gives preeminent place to formaltechnical knowledge and which assigns derivative status to the "practical" as a way of knowing. Rather than regarding the practical reasoning of the practitioner as simply a derivative of the formal knowledge advanced in the academy, my approach advances the epistemological status of "practical knowledge" as a distinct and identifiable mode of knowing in its own right. ${ }^{9}$ When this status is granted, the practical takes its place alongside the formal-technical as constitutive elements of professional knowledge.

Using primarily the work of critical theorist Jürgen Habermas on the manner in which differing domains of human interest create distinct forms of knowledge, ${ }^{10}$ I develop a conceptual model for examining differences between formal (technical) and practical (substantive) knowledge. ${ }^{11}$ The model advanced here is based on the epistemological premise that the differing functional interests of the technical and practical arenas of human activity mandate distinctly different forms of knowledge. Using the model, I go on to examine how these interests serve to organize knowledge with regard to the primary cognitive commitments involved, the categories and processes in which rationality is structured, the methods by which truth claims are authenticated, the type of discourse in which knowledge is typically communicated and extended, and, finally, the manner in which knowledge is most readily available to the knower. I use the work of Michael Polyani on tacit knowing, the contributions of Donald Schon regarding professional practice knowledge, and others, to further elaborate the model. ${ }^{12}$

\section{Philosophical Bases for Reclaiming the Practical}

The suggestion that practical knowledge and formal-technical knowledge are distinctly different forms of knowing is by no means a novel idea. In Nicomachean Ethics, Aristotle distinguished among technical, practical, and theoretical forms of reasoning. ${ }^{13}$ Technical (instrumental or meansends) rationality (techne) presupposes given ends, follows known rules, and uses given means to achieve those ends. It is both action and product. Making, manufacturing, mastering, and producing are action words associated with the technical, which is also the world of Hannah Arendt's homo faber. ${ }^{14}$

Practical reasoning, by contrast, does not assume known ends or given means. On the contrary, the ends may be ambiguous, and available means may be questionable or inadequate. Praxis is the form of reasoning appropriate to social, political, or other interactive contexts in which the individual, drawing on experience to provide a grasp of the immediate situation, reasons how to act prudently and correctly in a 
given set of circumstances. Prudence supersedes effectiveness as the relevant virtue in such cases. Indeed, the prudent person may be called on to make choices among several potentially effective (or equally ineffective) courses of action.

According to Aristotle, a third category of knowledge, theoretical reasoning, involves the pursuit of purely intellectual questions. Disciplines such as analytic philosophy or the so-called pure sciences require theoretical reasoning. Since social work research is not a pure science, this category of knowing is irrelevant to the present discussion.

From another intellectual tradition, sociologist and philosopher Habermas has developed a theory of science that makes explicit distinctions between technical and practical knowledge. His categories are defined in a manner overlapping those of Aristotle. ${ }^{15}$ The particular contribution of Habermas is the link he draws between distinct domains of human activity and the type of knowledge constituted by those domains. In other words, Habermas demonstrates a way to connect forms of knowing with modes of being and acting in the world. ${ }^{16}$

In Habermas's view, there are two initial ways in which human beings act on their world. ${ }^{17}$ Through production or instrumental action, individuals and collectivities attempt to shape the material and social world to satisfy their physical needs and desires. Through interaction or symbolic activity, individuals and communities strive to give meaning and coherence to their social existence. ${ }^{18}$ According to Habermasian epistemology, these domains of human activity are "knowledge constitutive." 19 That is to say, differences in the functional and cognitive interests of the actors in these two domains mandate fundamentally different modes of rationality. ${ }^{20}$ Corresponding to the instrumental domain is technical knowledge; corresponding to the interactive domain is practical knowledge.

When Habermas speaks of knowledge being constituted by the pragmatic interests and commitments of the actors in a specific domain of activity, what he means is that these interests structure the manner in which knowledge is organized and inquiry advanced. Which questions will be asked? Which data will emerge as "fact," and how is that fact to be defined? By what standards will knowledge be judged, and which reference groups will arbitrate such standards? For Habermas, these and similar questions cannot be answered in the abstract, but only with reference to the particular arena of human life and activity in which they are asked.

Habermas's principal objective of Knowledge and Human Interests is to promote the claims of the interpretive and the critical sciences over and against the empirical-analytical sciences as disciplines appropriate to the study of human social life. Thus, he is more concerned with establishing the interpretive sciences as a means for studying the interactive or practical domain than he is with elaborating practical 
rationality as a way of knowing in its own right. Nevertheless, his arguments provide a rationale and lay the groundwork for positing a form of knowledge and method of inquiry proper to the interactive sphere of human existence.

\section{Technical and Substantive Rationality and Discourse}

Let us consider this unexceptionable claim: the study of practice is not practice. From the perspective of the researcher-technician, social work practice is a phenomenon to be investigated; for the practitioner, it is lived experience. The difference is not simply a matter of quantity or quality of information available to the researcher or to the practitioner. It is not, for example, that the practitioner has an inside track to knowledge the outsider does not, or cannot, possess. Nor is it that the researcher has access to more reliable information. The critical issue is that the researcher and practitioner, respectively, have functionally different relationships to the practice arena and, therefore, differing cognitive interests for their involvement in that arena. ${ }^{21}$ These differing interests, in turn, result in characteristically different forms of rationality and discourse.

Broadly speaking, the instrumental, or technical, domain of activity refers to ways in which human beings seek to make the world they inhabit responsive to their needs and desires. In order to create the conditions in which needs are met and desires fulfilled, the criterion of effective control becomes the regulating principle. The accomplishment of given ends depends on correctly assessing the various means available to achieve those ends. Decision rules for action are based on some calculus of probability in reaching the stated goal. This mode of rationality is defined in terms of means-end or technical reasoning. ${ }^{22}$

If instrumental action requires analyzing the means relative to the ends for the purpose of control or management, it must also require some estimation of potential outcomes. That is to say, it requires the ability to make empirically verifiable predictions about events and behavior. Prediction can occur only when abstraction from the concrete situation is sufficient to permit generalization about regularities across other instances. Prediction, in turn, necessitates the structuring of situations into causes and effects. In order to predict, one needs to know that, if a particular state of affairs changes or is altered, another state of affairs will likewise be altered. At the same time, the imperatives of accuracy in predicting events dictate procedural standards that differentiate (or at least attempt to differentiate) between observed facts and the knowing subject's experience of those facts. ${ }^{23}$ The applied sciences offer the quintessential example of instrumental activity, with its accompanying mode of rationality. 


\section{Social Service Review}

By contrast with the formal-technical mode of reasoning appropriate to the instrumental sphere of human activity, the interactive, or practical, domain is characterized by a substantive rationality. Whereas the achievements of the instrumental domain are premised on an ability to successfully predict and organize outcomes and to operate at a level of abstraction that allows generalization from one singular event to other similar events, the interactive sphere has as its prime directive the need to understand the immediate meaning and implication of context. This understanding is necessary for the kind of deliberation in which decision rules are discovered within the evolving context itself, instead of being formulated a priori. Various expectations, commitments, and understandings converge on the decision moment, along with the constraints of resource, resolve, and perception.

If the applied sciences epitomize the achievements of technical reasoning, professional practice in the human and social services exemplifies the accomplishments of practical rationality. The social work practitioner attempting to decide in a specific, concrete case how to reconcile issues of client confidentiality with mandates to report dangerousness engages in practical reasoning, as does the politician (in Aristotle's sense) who must make a decision on behalf of the community, given multiple constituencies and multiple issues. Such decisions are seldom derived through an algorithmic application of general rules to the specific instance. Indeed, the case may be made that simple, linear applications of theory to the concrete case are more frequently the mark not of the expert but of the novice professional, one who is either unaware of the complexities or unable to systematically take them into account. ${ }^{24}$

If the linear equation provides a convenient metaphor for technical rationality, the most appropriate metaphor for substantive rationality is the hologram. Substantive rationality involves an emerging recognition or discovery of the multidimensional structure, shape, and significance of a problem. Jerome Bruner suggests that "we solve a problem or make a discovery when we impose a puzzle form on a difficulty and convert it into a problem that can be solved in such a way that it gets us where we want to go." ${ }^{25}$ Problem solving in complex, interactional situations occurs when what Bruner terms "puzzle forms," or combinations of such forms, are tried out for goodness of fit with the structure of a concrete problem. Substantive rationality may be described as the dialectical process in which the emerging recognition of the structure of a problem and the imposition of "puzzle forms" interact in some combination that, if successful, results in tentative solutions. In the unproblematic case and for the experienced professional, an appreciation for goodness of fit generally occurs at a tacit level of awareness. ${ }^{26}$

In the perspective adopted here, the substantive knowledge employed in practice may be understood in part as a specialized, systematized, 
and sanctioned form of praxis, ordinary interactional know-how. Thus, Martin Rein and Sheldon White maintain: "Praxis is what everybody knows how to do and does in a society. Practice consists of a system of actions unique to and institutionally vested in a professional role; it occurs when social behavior is drawn from the general behavior of the society and segregated into a professional preserve." ${ }^{27}$ This view of practical knowledge identifies the real world connection between professional practice and "naive" praxis at the same time that it defines differences between the two. Similarly, just as practice is an extension of praxis, scientific knowledge is an extension of techne, the commonsense knowledge human beings bring to bear in making their environment work for them. ${ }^{28}$ Like the practitioner, the technician or scientist brings all her or his native, technical know-how and common sense to focus on the scientific project. She or he does not leave this ordinary human "equipment" at the door of the laboratory.

Thus, it is not, as some intimate, ${ }^{29}$ that practice (and practical rationality) retains connectedness with ordinary life experiences, whereas science (and technical rationality) does not. The roots of both science and practice are to be found in the everyday processes and achievements of human beings who seek to manage (techne) their world and to orient their action (praxis) in relation to others in that world.

\section{Methodology: Objective or Contextual}

Thomas Nagel suggests that some of the most central problems of human knowledge derive from the following question: "how to combine the perspective of a particular person inside the world with an objective view of that same world, the person and his viewpoint included." 30 The critical issue is the relationship of the knowing subject to that which is known. The natures of the technical project (techne) and of the practical project (praxis) dictate different resolutions to this problem. Lest the reader understandably, but erroneously, anticipate that I will try to correlate the technical-practical dichotomy with the objectivesubjective distinction, let me be clear that I will propose an alternate view.

With Nagel, I define subjectivity and objectivity as methods of understanding and securing knowledge and only secondarily as the products of that understanding. With Nagel, too, I view the distinction between the subjective and the objective as a matter of degree. ${ }^{31} \mathrm{~A}$ method of understanding is defined as subjective if it relies largely on the perspective of the singular knower. A method for securing knowledge may be characterized as more objective than another the less it depends "on the specifics of the individual's makeup and position in the world or on the character of the particular type of creature he is." 32 Whereas 


\section{Social Service Review}

the essence of the objective lies in replicability, the subjective is defined in terms of its singularity.

Earlier I suggested that the functional and pragmatic commitments of technical knowledge dictate a methodology that brackets the subjectivity of the knower from that which is known. That is to say, the methodological stance of the technical is an objective one. This objective approach is the basis of all scientific inquiry (qualitative as well as quantitative).$^{33}$ Its methods are, in the first place, an effort to guarantee the integrity of what is known as distinct from the perspective of the one who knows. Without this kind of objectivity, there would be no basis for accepting the conclusions of the knower apart from the strength of his or her word. More pragmatically, there would be no basis for assuming that the causal claims of the investigator are related to actual patterns of occurrence, patterns which, in turn, support generalization and prediction.

Yet, as we know, there are limits to scientific objectivity. As Nagel maintains, the goal to give an account of the world from a perspective that transcends particular points of view is realizable only by approximation because "we ourselves are the first obstacles to such an ambition." ${ }^{34}$ Scientific objectivity is sought not by denying the subjectivity of the researcher-technician, which in any event cannot be denied. Instead, it is secured by adopting an objective attitude in which one acknowledges the limitation of singular standpoints by applying rigorous, procedural safeguards. Controls for ensuring the reliability and validity of investigation contribute to this kind of objectivity, as does the fundamental, critical stance that submits even one's most cherished hypotheses to empirical validation. ${ }^{35}$

It is common to find references in the literature suggesting that, whereas scientific (technical) knowledge is objective in nature, practice knowledge is, and cannot help but be, subjective. ${ }^{36}$ This suggestion betrays a naivete about the complexity of knowing in practice. The suggestion becomes even more problematic once we recognize that the word "subjective," like the word "objective," has several definitions that are not always clear, even in context. Although by no means an exhaustive list, the following meanings may be implied when the term "subjective" is used to describe practice knowledge: (1) a view from the perspective of a knowing subject (the "I"); (2) an unwarranted or even premeditated contamination of that which is known by the partisan interests of the knowing subject (biasing, prejudicing); and (3) an assumption that the world of the knowing subject is the true and only reality (solipsism, narcissism, as in the phrase "hopelessly subjective").

Subjectivity, in the latter two meanings of the term, is as unacceptable in practice as it is in research. Like the researcher, the practitioner employs a variety of procedures to establish and maintain objectivity 
over subjectivity in the negative sense of the term. Role definitions, reciprocal expectations, measures of accountability, and standards for professional conduct are among the means employed to protect the achievements of practice knowledge from particularist claims. However, if the term subjectivity refers simply to the perspective of the knowing subject, the issue becomes more complicated. Is practical knowledge subjective in this latter meaning of the term? The answer is probably as much "yes" as it is "no."

In Habermasian terms, practical reason is the form of rationality proper to the interactive arena of human life. In this arena, knower and known are involved in the same social, cultural, and symbolic experiences and are, thus, accomplices in the activity of creating and understanding meanings. As Charles Horton Cooley long ago suggested: "We learn to know human life outwardly and inwardly and at the same time and by a single process." ${ }^{37}$ In the world of praxis, the personal perspective of the knower must be gleaned for all the understanding it yields about a meaning-world he or she knows intimately. By contrast with technical knowledge, which requires that the subjective self of the knower be systematically set aside, practical knowing is pursued, in part, through the subjective involvement of the one who knows and acts. The personal standpoint of the individual engaged in praxis yields a knowledge critical to effective, practical action.

However, knowledge from the subjective standpoint of the knower is itself insufficient for effective practice. Detachment from that point of view is equally critical. Any interactive situation supplies multiple, possibly valid, perspectives. These perspectives are available only to the individual who is able (and willing) to relinquish the personal standpoint. There is a form of objectivity, as Nagel suggests, that "allows us to transcend our particular viewpoint and develop an expanded consciousness that takes the world in more fully." 38 In this form of objectivity, the central conceptual task requires the practitioner to detach from his or her partial and personal perspective and remain open to and aware of other perspectives. ${ }^{39}$ The central ethical task requires that the practitioner simultaneously recognize other subjects whose understandings limit and objectify one's own. ${ }^{40}$ The ultimate task, however, is for the practitioner to accomplish conceptual and ethical objectivity while retaining commitments to his or her own viewpoint as valid and applicable.

Practitioners who engage in clinical intervention with families, for example, frequently speak of "joining with" the family. At one level, "joining with" implies that the worker develop a subjective understanding of what it is like to be part of a particular family system. The activity of joining with, however, is incomplete without "standing apart." The clinician must become both insider and outsider to the knowledge the 


\section{Social Service Review}

family has of itself. In this as in other situations, the clinical practitioner must rely on subjective knowledge as well as on sources of understanding that transcend and condition the personal perspective.

Thus, it is only partially true to say that practice knowledge is subjective. In order to take effective action, the practitioner must be able to move from the subjective perspective to an objective view of that perspective, and back again. This implies that the practitioner must be able to view even his or her own perspectives "from the outside, as events in the world." 41 The epistemological stance in practice is contextual; both the subjectivity of the practitioner-knower and the objective imperatives of the context must be figured into the sum of what is known.

\section{Explicit or Tacit Knowledge}

Ever since Descartes, a separation between thinking and doing has been etched into the Western intellectual tradition. Descartes's dictum made cognition ontologically and logically prior to being and acting. Debates in the literature between research and theory, on the one hand, and practice, on the other, are a legacy of this tradition in which action is assumed to follow thought. This understanding of the relationship between thinking and acting is generally presumed in the social work literature with few exceptions. ${ }^{42}$ Within certain other disciplines, however, this view has been sharply challenged. ${ }^{43}$ One of the more central works in this challenge has been Polyani's exposition of the personal and tacit dimension of human knowing. ${ }^{44}$

Polyani's distinction between two kinds of awareness, focal awareness and subsidiary awareness, is important for the discussion here. According to Polyani, in any activity, we are focally aware of whatever is the object of our activity; we have a subsidiary awareness of that which serves as "instrument." For example, in using a hammer to drive a nail, "We watch the effect of our strokes on the nail and try to wield the hammer so as to hit the nail most effectively. When we bring down the hammer we do not feel that its handle has struck our palm but that its head has struck the nail.... I have a subsidiary awareness of the feeling in the palm of my hand which is merged into my focal awareness of my driving in the nail." "T5 "Tool," of course, is not limited to artifact; a concept, a theory, a skill may form part of our subsidiary awareness in performing an activity. What Polyani suggests about the knowledge implicit in skills, he also applies to the knowledge embodied in the judgments of the experienced professional-the deliberations of the judge, the diagnostic acumen of the physician. ${ }^{46}$

Polyani's arguments about the tacit dimension of professional knowledge are supported by expert systems research. Expert systems 
are computer programs that attempt to replicate "how an expert knows what he knows." 47 In order to design these programs, investigators must first study how experts in a circumscribed area of knowledge solve problems. It appears that an important part of how an expert knows is known unconsciously. James F. Brule and Alexander Blount, for example, maintain that "abstract generalizations about successful operation in the domain the expert knows will not be available generally to consciousness." 48

When something or some activity is the object of focal awareness, it cannot at the same time be the object of subsidiary awareness, and vice versa. While attending to the whole, we are only subsidiarily aware of any one part or element of the whole. The pianist who concentrates on the position of fingers and keys will lose the sonata. ${ }^{49}$ The social worker who focuses attention on the technique of empathic responding rather than on the state of the client or on the objectives of the interview will find that his or her responses seem awkward and staged. In the unproblematic case, the knowing-in-action of the practitioner is a unitary act in which the theories, constructs, cognition, and skills of the knower are embedded as subsidiary processes, while the focal awareness is tuned to the activity as a whole or to the objectives of that activity.

Whereas substantive knowledge is tacit and embodied in action, formal knowledge is explicit, propositional, and discursive. It is outside ourselves. We can point to it in texts and other scholarly works. Even when there is disagreement within a discipline over the truth claims of a particular proposition, it is knowledge that has been sanctioned by a community of scholars as legitimate for discourse. By contrast with practical knowing, which, when used, is embedded in experience, formal knowledge is "out there" as the "adjudicated products of disciplined inquiry." 50

In describing the typical form in which practical and formal knowledge are available to the knower, two important clarifications are in order. First, it would be mistaken to assume that, because formal knowledge is explicitly recognized within a discipline as legitimate for scholarly debate and inquiry, its truth claim is more valid or more reliable than that of the practical. As argued earlier, both are reliable and valid, although different, forms of knowing. Similarly, both are subject to error. Second, it would be inaccurate to conclude from the present arguments that practical knowledge is always or must remain tacit and unavailable to our reflective selves. On the contrary, as Schon has maintained, particularly in situations of ambiguity or novelty, "our thought turns back on the surprising phenomenon, and at the same time, back on itself," as a form of "reflection-in-action." is, in fact, one of the ways that practice knowledge becomes refined and extended into what the literature rather loosely terms practice wisdom. ${ }^{52}$ 
It is clear, however, that, given the differences between these two forms of knowledge, an essentially cognitive interpretation of practice knowing will not be effective. We already are aware that the correlation between academic achievement and professional performance is not always a direct one. ${ }^{53}$ As Michael Connelly and D. Jean Clandinen suggest, "If concepts are learned as concepts, they are not necessarily submerged, but remain visible and identifiable, and may be recalled ... for achievement tests. .. . But from the perspective of the user, precise recall may be a sign of incomplete learning. It is a sign that concepts have been learned as concepts ... and that they are, therefore, not 'on call' except in the lesser sense of recall upon demand." 54

Whether learned as ordinary praxis or acquired as specialized practice, practical knowing, the skills and reasoning the practitioner applies in action, is most readily usable when implicit in the act as "tool." With due regard for any reduction involved, it may be said that such knowledge is embodied in the act and the actor. Whatever else this formulation suggests, it advances a notion of the relationship between knowing and acting that is less linear and more reciprocal than is normally assumed in the literature on professional knowledge.

\section{Some Implications and a Rapprochement}

In an early work, dealing with field learning in the various professions, Kenneth D. Benne noted, "Western epistemologists, working for the most part, in modern times, in universities, have not drawn their models of valid 'knowing' from the methods and products of thinking men and women of action who guide, direct, and conceptualize the practical 'makings' and 'doings' of culture and society." ${ }^{55}$ Benne goes on to suggest that conflicts the student may experience in attempting to bridge the academic and practice arenas are as much a result of cognitive differences between these two "worlds" as of attitudinal and affective differences. ${ }^{56}$

The understanding of what it means to know-in-practice, as developed in this article, supports Benne's contention. Basing my major arguments on Habermasian critical theory, Polyani's concept of "tacit knowledge," and Schon's model of reflective practice, I maintain that the academic and practitioner have functionally different relationships to the practice arena and, therefore, differing cognitive interests for their involvement in that arena. These differing interests are assumed to determine the categories in which knowledge is structured, the methods by which truth claims are established, the type of discourse in which knowledge is typically communicated, and, finally, the form in which knowledge is available to the knower. Thus, I advance a claim for the nonderivative status of the practical (substantive) alongside the formal in definitions of what constitutes professional knowledge. 
The orientation that defines practice knowledge largely in terms of applied technical knowledge has been challenged elsewhere in the literature ${ }^{57}$ My position is that such challenges do not go far enough in addressing the realities of how practitioners know-in-practice. I contend that, as a profession, our underestimation of the extent of the discontinuity between the cognitive-functional commitments of the technical and of the practical has contributed to our limited success in bridging these two arenas of human activity.

How then are these different, cognitive "worlds" reconciled? Distinctions that some anthropologists make between "experience-distant" and "experience-near" categories of meaning may be pertinent to this question. ${ }^{58}$ In Clifford Geertz's term, "experience-near" categories are those that an individual "might himself naturally and effortlessly use to define what he or his fellows see, feel, think, imagine, and so on." "Experience-distant" constructs are those that "specialists employ to forward their scientific, philosophical . . a aims." ${ }^{\circ 0}$ The terms "constructs" and "categories" are intended to include not just language per se, but all those forms and procedures that communities and individuals use to organize inquiry and to structure and communicate knowledge.

The argument proposed here is a pragmatic one. The reality is that, when theory and research move to application, experience-distant categories are (and must be capable of being) folded into categories that are experience-near. On the surface, this formulation should be self-evident. What may be less evident is my central argument. The task of translating the "vernacular" of research into the idiographic immediacies of practice has seldom been an easy one. The suggestion is that this task will become somewhat less arduous when the distinct, cognitive status of practical knowledge is clarified and more explicitly understood. Ultimately, for the human service practitioner it is the functional commitments of the practical that mandate both the categories of rationality required in practice and the expression of that rationality in action.

In advocating a perspective that grants legitimacy to substantive knowledge alongside the formal in defining professional knowledge, I raise a number of questions for social work practice, professional education, and social work inquiry. Although a complete elaboration of these questions is beyond the scope of the present discussion, it is possible to sketch several of the issues that emerge.

1. I argue that technical-conceptual knowledge is part, but only part, of the total calculus of professional knowledge. Much of the knowledge that the professional uses as he or she goes about the business of practice is built on his or her own cultural store of "naive" praxis. ${ }^{61}$ Even more of what the professional knows has been constructed in an ongoing, but often implicit, manner in the course of professional practice. ${ }^{62}$ If this is the case, then critical reflexivity on the part of the 
professional becomes all the more urgent. As Schon maintains, "Many practitioners, locked into a view of themselves as technical experts, find nothing in the world of practice to occasion reflection.... For them, uncertainty is a threat; its admission a sign of weakness. Others ... feel profoundly uneasy because they cannot say what they know how to do, cannot justify its quality or rigor." 63

As defined here, critical reflexivity involves the practitioner-knower in the process of making explicit the knowledge that is implicit in action so that it becomes available for both critique and inquiry. ${ }^{64}$ The effort called for includes, but goes well beyond, the task of outcome evaluation. The importance of reflecting on professional activity and on the knowing that is embodied in that activity cannot be overstated. The advancement of professional knowledge (writ large and small) requires this ongoing process.

2. Models for defining the relationship between classroom and field reveal underlying assumptions regarding practice knowledge ${ }^{65}$ When the technical definition of practice knowledge dominates, the field practicum experience is viewed primarily as the location in which the student "road tests" conceptual knowledge acquired in the classroom. When practical (substantive) knowledge is assumed to define professional learning, the field experience approximates an apprenticeship.

With the expanded epistemology proposed here, instructional models that reflect more or less exclusively either the technical approach to field education or the practical paradigm must be challenged as partial and limited. From this viewpoint, both formal (received) knowledge and knowledge constructed in practice require emphasis in professional education. The practicum becomes the location nonpareil for learning how social workers actually go about the business of constructing knowledge and of incorporating "received" knowledge as part of that construction. An implicit appreciation of this practicum function may be part of the reason why social work students and practitioners continue to attribute their most significant professional learning, not to the classroom, but to the field experience, and why they do so even within the dominant shadow of the technical paradigm. ${ }^{66}$

3. The social work literature has demonstrated a commitment to locating and prescribing new research models for the practitioner. ${ }^{67}$ Efforts in the literature to discover methods of inquiry consistent with the cognitive commitments of the practicing professional are to be applauded. However, it should be stressed that current single-subject models are probably not the final word on the issue of appropriate paradigms for practice-based research. Schon, for example, argues that there is an implicit, but nevertheless systematic, form of investigation that the practitioner routinely applies during the course of practice: "[the practitioner] reflects on the phenomena before him, and on the prior understandings which have been implicit in his behavior. $\mathrm{He}$ 
carries out an experiment which serves to generate both a new understanding of the phenomena and a change in the situation." 68 Schon argues that the interests of knowledge generation would be well served were researchers to undertake a study of how practitioners do, in fact, perform inquiry-in-action. ${ }^{69}$

One concluding point is in order. I have addressed discontinuities between the world of the practitioner and that of the academic from an epistemological perspective. This approach is consistent with that of a number of other authors who have discussed the differences involved as epistemological or paradigmatic in nature. ${ }^{70}$ However, there is a political-ideological dimension to the issues involved as well, a dimension that one ignores at risk. ${ }^{71}$

From the perspective of techne, social work is not only a phenomenon to be investigated, it is a phenomenon to be improved. Thus, the practice arena supplies both the "raw" material for study and the market for knowledge and ideas. The practitioner becomes consumer, and human technology becomes product or commodity. It is at this point that the functional commitments of the technical domain are in danger of becoming not simply pragmatic interests, but ideological investments. When the practice world is viewed primarily as a derivative of the technical, servicing its research needs and providing a market for its products, the metaphor evoked is one of colonization. For those who take issue with this metaphor as perhaps too strongly stated, a brief content analysis of the literature on practice research is recommended. ${ }^{72}$

I suggest that the marketing of (and hard-sell approaches to) social work technology will become less necessary the more researchers respect the actual processes by which the practitioner comes to know-in-practice. The desired end product of this mutuality will be a more productive research enterprise and a practice arena that contributes more substantially to informing its own conceptual bases.

\section{Notes}

1. Martin Rein and Sheldon H. White, "Knowledge for Practice," Social Service Review 55 (March 1981): 1-41. For a succinct history of the rise of the technical paradigm within the professions, see Donald Schon, The Reflective Practitioner: How Professionals Think in Action (New York: Basic, 1983), pp. 3-69.

2. David M. Austin, "The Flexner Myth and the History of Social Work," Social Service Review 57 (September 1983): 357-77; Helene Reinherz, Joseph M. Regan, and Jeane W. Anastas, "A Research Curriculum for Future Clinicians: A Multimodal Strategy," Journal of Education for Social Work 19 (Spring 1983): 35-41.

3. David M. Austin, "Research and Social Work: Educational Paradoxes and Possibilities," Journal of Social Service Research 2 (Winter 1978): 159-76; Martin Bloom, "Challenges to the Helping Professions and the Response of Scientific Practice," Social Service Review 52 (December 1978): 584-95; Scott Briar, "The Casework Predicament," Social Work 13 (January 1968): 5-11; Joel Fischer, "Is Casework Effective? A Review," Social Work 18 (January 1978): 5-20; Stuart A. Kirk, Michael J. Osmalov, and Joel 
Fischer, "Social Workers' Involvement in Research," Social Work 21 (March 1976): 121 -24; Aaron Rosenblatt, "The Practitioner's Use and Evaluation of Research," Social Work 18 (January 1968): 53-59.

4. Eileen D. Gambrill and Richard P. Barth, "Single-Case Study Designs Revisited," Social Work Research and Abstracts 16 (Fall 1980): 15-20; Michael W. Howe, "Casework Self-Evaluation: A Single-Subject Approach," Social Service Review 48 (March 1971): 1-24; Jill Doner Kagle, "Using Single-Subject Measures in Practice Decisions: Systematic Documentation or Distortion?" Arete 7 (Winter 1982): 1-9; Rona Levy and D. Olson, "The Single-Subject Methodology in Clinical Practice: An Overview," Journal of Social Service Research 3 (Fall 1979): 25-49; Elizabeth A. R. Robinson, Denise E. Bronson, and Betty J. Blythe, "An Analysis of the Implementation of Single-Case Evaluation by Practitioners," Social Service Review 65 (June 1988): 285-99; Roy A. Ruckdeschel and Buford E. Farris, "Assessing Practice: A Critical Look at the Single-Case Design," Social Casework 62 (1981): 413-19; Edwin J. Thomas, "Research and Service in Single-Case Experimentation: Conflicts and Choices," Social Work Research and Abstracts 14 (Winter 1978): 20 -31; Sidney E. Zimbalist, "The Single-Case Clinical Research Design in Developmental Perspective: Mainstream or Tangent," Journal of Education for Social Work 19 (Winter 1983): 61-66.

5. Aaron H. Beckerman, "Differentiating between Social Research and Social Work Research: Implications for Teaching," Journal of Education for Social Work 14 (Spring 1978): 9-15; Ruth G. Dean and Barbara L. Fenby, "Exploring Epistemologies: Social Work Action as a Reflection of Philosophical Assumptions," Journal of Social Work Education 25 (Winter 1989): 46-54; Glenn O. Haworth, "Social Work Research, Practice, and Paradigms," Social Service Review 58 (September 1984): 343-57; Martha Brunswick Heineman, "The Obsolete Scientific Imperative in Social Work Research," Social Service Review 55 (September 1981): 371-97; Walter H. Hudson, "Scientific Imperatives in Social Work Research and Practice," Social Service Review 56 (June 1982): 246-58; Roberta Wells Imre, "The Nature of Knowledge in Social Work," Social Work 29 (January-February 1984): 41-45; John R. Schuerman, "Debate with Authors: The Obsolete Scientific Imperative in Social Work Research," Social Service Review 55 (December 1981): 144-48. Partisan positions on these and similar issues have been summarized adequately elsewhere. See Colin Peile, "Research Paradigms in Social Work: From Stalemate to Creative Synthesis," Social Service Review 62 (March 1988): 1-19.

6. I distinguish between a phenomenological study of how practitioners know-inpractice and a phenomenological understanding of the practice arena. A number of authors have used phenomenological understandings to point out differences between the practice and research arenas. Rein and White (n. 1 above) are an example, as are Beckerman (n. 5 above) and Heineman (n. 5 above). My point is that, although the literature has explored differences between the enterprise of research and that of practice, it has not given sufficient attention to studying precisely how practitioners construct knowledge and decisions in action. See Schon, The Reflective Practitioner (n, 1 above), pp. 320-23.

7. The fact that this perspective has been largely neglected is not surprising given what the sociology of the professions has to tell us about the status politics of professional life. The trend toward lodging the formal-theoretical base for practice increasingly in the academy rather than in the practice arena is consistent with the profession's efforts to establish and secure legitimacy as a profession. For a further discussion of these and similar themes, see Randall Collins, The Credential Society: An Historical Sociology of Education and Stratification (New York: Academic Press, 1979), pp. 131-81. For related arguments in the social work literature, see H. Jacob Karger, "Science, Research and Social Work: Who Controls the Profession?" Social Work 28 (May-June 1983): 200-205. See also Austin, "Research and Social Work" (n. 3 above).

8. Donald Schon, Educating the Reflective Practitioner (San Francisco: Jossey-Bass, 1987), p. 13.

9. Jürgen Habermas, Knowledge and Human Interests, trans. Jeremy J. Shapiro (Boston: Beacon, 1971), Theory and Practice, trans. J. Viertel (London: Heineman, 1974); Jack Mezirow, "A Critical Theory of Adult Learning and Education," Adult Education 32 (Fall 1981): 3-24.

10. Habermas, Knowledge and Human Interests (n. 9 above). 
11. It should be underscored for the sake of clarity that this distinction between formal-technical and practical (or substantive) knowledge is not the same as differences drawn elsewhere in the literature between empirical and normative approaches to research, or between quantitative and interpretative research methodologies. Proponents of both the empirical and the interpretative in social work research conduct their debate within terms bounded by a formal-technical mode of rationality. Whatever their differences, researchers from both the positivist and the interpretivist traditions consider (must consider) social work as a phenomenon to be studied systematically with a view to the application of knowledge thus generated. It is consistent with the functional commitments of applied science to regard the field of activity in this way. In the sense in which I will come to define these terms, the technical, not the practical, is the most immediate venue of social work research. This is the case, no matter what the epistemological or methodological persuasion of the researcher. By contrast, the practical, and its form of rationality, is the province of the practitioner, precisely in his or her professional capacity.

12. Michael Polyani, The Study of Man (Chicago: University of Chicago Press, 1959), Personal Knowledge: Towards a Post-critical Philosophy (Chicago: University of Chicago Press, 1962); Schon, The Reflective Practitioner (n. l above), and Educating the Reflective Practitioner (n. 8 above).

13. Aristotle, The Ethics of Aristotle: The Nicomachean Ethics, trans. J. A. K. Thomson (New York: Viking Penguin, 1976).

14. Hannah Arendt, The Human Condition (Garden City, N.Y.: Doubleday, 1959).

15. This is not to suggest that Habermas is neo-Aristotelian in his thought, a position he himself makes quite clear in Knowledge and Human Interests (n. 9 above), pp. 41-42. Habermas's work may be viewed best against the intellectual backdrop of Marxist theory and the German humanist tradition, including Wilhelm Dilthy, Selected Writings, ed. H. P. Rickman (Cambridge: Cambridge University Press, 1976); Karl Mannheim, Essays on the Sociology of Knowledge (London: Routledge \& Kegan Paul, 1952); and Max Weber, Max Weber: The Theory of Social and Economic Organization, trans. A. M. Henderson and Talcott Parsons, ed. Talcott Parsons (New York: Free Press, 1964). This latter tradition argued the case for fundamental, epistemological differences between the natural and the human sciences.

16. See esp. Habermas, Knowledge and Human Interests (n. 9 above), chap. 3.

17. Habermas included yet another category of rationality in his list of cognitive domains. Habermas termed this third type of knowledge the "emancipatory." Emancipatory reasoning is a way of reflecting on disjunctures (in critical theory's neo-Marxist terms, "lack of correspondence") between the formal rationality of the technical arena of human activity and the substantive rationality of the practical domain. It is clear in context that, for Habermas, emancipatory knowledge takes on a metatheoretic position relative to the other two modes of rationality. See Habermas, Knowledge and Human Interests (n. 9 above), pp. $314 \mathrm{ff}$. For this reason, although I recognize the centrality of this concept in Habermas's thought, I exclude explicit discussion of the "emancipatory" as a mode of knowing. However, the importance of reflecting on the actual conditions of social life and the symbolic meanings we assign those conditions is presumed throughout the article.

18. In developing the distinction between productive and symbolic activity, Habermas rejects the simpler Marxist notion that forms of consciousness are completely determined by forms of social-productive life. For Habermas, the productive (economic structures) and the symbolic (consciousness) are codetermined.

19. Habermas, Knowledge and Human Interests (n. 9 above), p. 311.

20. Habermas is clear in his assertion that knowledge is constituted not only by the functional commitments of those engaging in a particular human enterprise but by their ideological interests as well. Although recognizing the importance of the topic, I will only briefly address the ideological element in the constitution of knowledge. To do more than this would be to go well beyond the intended scope of the article. See Karger (n. 7 above) for a discussion of ideology and power in social work practice and research.

21. The terms "practitioner" and "researcher" are used to define roles and functions, not role incumbents. I want to be very clear that nothing in my argument is intended to suggest that the same individual cannot take on both roles. However, the pragmatic 


\section{Social Service Review}

and cognitive commitments of an individual engaged in technical research will differ from those of that same individual when he or she is engaged in direct practice. I suggest that, as a profession, our underestimation of the discontinuity between these differing interests has contributed to our limited success in reconciling their claims. What I propose is that forms of inquiry more consistent with the cognitive commitments of the practitioner should be explored, elaborated, and encouraged. See Schon, The Reflective Practitioner (n. 1 above), pp. 320-23.

22. Habermas's notion of technical rationality is similar to Max Weber's concept of zweckrationales action. Weber (n. 15 above), p. 117, defines this term as "action ... oriented to a system of discrete individual ends ... when the ends, the means, and the secondary results are all rationally taken into account and weighed. This involves rational consideration of alternative means to the end, of the relations of the end to other prospective results of employment of any given means, and finally of the relative importance of different possible ends."

23. The proposition that a separation between subject and object, knower and known is either possible or desirable in the cultural sciences is vigorously challenged by Habermas. For Habermas, assertions to this effect are not only inaccurate, but, more important, they constitute an ideological pretense, masking particular but unacknowledged interests within that portion of the research community that endorses such notions. See Habermas, Knowledge and Human Interests (n. 9 above), pp. 301-17.

24. Michael Connelly and D. Jean Clandinin, "Personal Practical Knowledge and the Modes of Knowing: Relevance for Teaching and Learning," in Learning and Teaching the Ways of Knowing, ed. Elliot Eisner (Chicago: University of Chicago Press, 1985), p. 182. Literature in the area of expert systems research is also relevant to this argument. For example, James F. Brule and Alexander Blount, Knowledge Acquisition (New York: McGraw-Hill, 1989), pp. 32-38, borrowing from Gregory Bateson, make a distinction between level I and level II knowledge. Level II knowledge, which characterizes the expert, is metaphoric in structure, rather than linear.

25. Jerome S. Bruner, On Knowing: Essays for the Left Hand (New York: Atheneum, 1962), p. 93.

26. Brule and Blount (n. 24 above), p. 37.

27. Rein and White (n. 1 above), p. 4.

28. Philosophers of differing schools of thought support this point. In this regard, Karl Popper, in The Logic of Scientific Discovery (New York: Harper Torchbooks, 1968), p. 22, cites a number of epistemologists who concur: "Kant, Whewell, Mill, Peirce, Duhem, Poincaré, Meyerson, Russell, and - at least in some of his phases - Whitehead. Most of those who belong to this group would agree that scientific knowledge is the result of the growth of common-sense knowledge. . . F For it is common-sense knowledge writ large, as it were."

29. Rein and White (n. 1 above), p. 4.

30. Thomas Nagel, The View from Nowhere (New York \& Oxford: Oxford University Press, 1986), p. 3.

31. Ibid., p. 5.

32. Ibid.

33. Jerome Kirk and Marc L. Miller, Reliability and Validity in Qualitative Research, Sage University Paper Series on Qualitative Research Methods, vol. 1 (Beverly Hills, Calif.: Sage, 1986).

34. Nagel (n. 30 above), p. 13.

35. As Kirk and Miller suggest (n. 33 above), p. 20, "Objectivity is the simultaneous realization of as much reliability and validity as possible."

36. Beckerman (n. 5 above); and Peile (n. 5 above).

37. Charles H. Cooley, "The Roots of Social Knowledge," American Journal of Sociology 32 (1926): 65.

38. Nagel (n. 30 above), p. 5.

39. Ibid., p. 20.

40. Ibid., p. 140.

41. Ibid., p. 20.

42. See, e.g., Martin Rein and Lisa Peattie, "Knowledge for Policy," Social Service Review 55 (December 1981): 526. 
43. For examples within the philosophical and educational literature, see John Dewey, Experience and Education (New York: Macmillan, 1963); Henry A. Giroux, "Postmodernism and the Discourse of Educational Criticism," Journal of Education 170 (Winter 1988): 5-30; and Joseph J. Schwab, "The Practical: Arts of Eclectic," School Review (August 1971): 493-542.

44. Polyani, Personal Knowledge (n. 12 above).

45. Ibid., p. 55.

46. Ibid., p. 54.

47. Brule and Blount (n. 24 above), p. 23.

48. Ibid., p. 37.

49. Polyani, Personal Knowledge (n. 12 above), p. 56.

50. Connelly and Clandinin (n. 24 above), p. 178.

51. Schon, Educating the Reflective Practitioner (n. 8 above), p. 28.

52. See Yosikazu S. DeRoos, "The Development of Practice Wisdom through Human Problem-solving Processes," Social Service Review 64 (June 1990): 276-87. Unfortunately, terms such as "practice wisdom" tend to minimize the distinct, cognitive status of practice knowing. Schon, Educating the Reflective Practitioner (n. 8 above), p. 13, maintains that "outstanding practitioners are not said to have more professional knowledge than others but more 'wisdom,' 'talent,' 'intuition,' or 'artistry'. . . . such terms as these serve not to open up inquiry but to close it off. They are used as junk categories, attaching names to phenomena that elude conventional strategies of explanation."

53. Richard K. Wagner and Robert J. Sternberg, "Practical Intelligence in Real-World Pursuits: The Role of Tacit Knowledge," Journal of Personality and Social Psychology 49 (1985): 436-58.

54. Connelly and Clandinin (n. 24 above), p. 184.

55. Kenneth D. Benne, "Educational Field Experience as the Negotiation of Different Cognitive Worlds," in The Planning of Change, ed. Warren G. Bennis, Kenneth D. Benne, Robert Chin, and Kenneth E. Corey (New York: Holt, Rinehart, \& Winston, 1976), p. 167.

56. Ibid., p. 166.

57. Rein and White (n. 1 above); DeRoos (n. 52 above); Schon, The Reflective Practitioner (n. 1 above), and Educating the Reflective Practitioner (n. 8 above).

58. Clifford Geertz, Local Knowledge: Further Essays in Interpretive Anthropology (New York: Basic, 1983).

59. Ibid., p. 57.

60. Ibid.

61. Rein and White (n. 1 above).

62. Schon, The Reflective Practitioner (n. 1 above), and Educating the Reflective Practitioner (n. 8 above).

63. Schon, The Reflective Practitioner (n. 1 above), p. 69.

64. Ibid.

65. Benne (n. 55 above).

66. Alfred E. Kadushin, "Introduction," in Field Education in Social Work: Contemporary Issues and Trends, ed. Dean Schneck, Bart Grossman, and Urania Glassman (Dubuque, Iowa: Kendall/Hunt, 1990), p. 11.

67. See n. 4 above.

68. Schon, The Reflective Practitioner (n. 1 above), p. 68.

69. Ibid., pp. $320-23$.

70. For epistemological differences, see, e.g., Dean and Fenby (n. 5 above); and Imre (n. 5 above). For paradigmatic differences, see, e.g., Haworth (n. 5 above); and Peile (n. 5 above).

71. Both Heineman (n. 5 above) and Karger (n. 7 above) speak to the political and ideological issues involved.

72. See, e.g., Robinson, Bronson, and Blythe (n. 4 above), p. 295. These authors use a marketing metaphor in discussing technology diffusion and implementation, specifically, practitioner use of single-case evluations: "By utilizing market segmentation, consumer research, communication concepts, and incentives theory, the response of target groups can be maximized." 